\title{
O ENSINO DE GEOGRAFIA NOS TRABALHOS APRESENTADOS NO XI ENANPEGE
}

\author{
The geography teaching in the papers presented at XI Enanpege \\ La enseñanza de geografía en trabajos \\ presentados en nel XI Enanpege
}

\section{Helena Copetti Callai}

Doutora em Geografia pela Universidade de São Paulo - USP. Professora na Universidade de Ijuí - UNIJUÍ e atua no Programa de Pós-Graduação em Educação da UNIJUI. Departamento de Humanidades e Educação UNIJUI- Rua do Comércio, 3000, Bairro Universitário, Ijuí-RS, 98700-000 E-mail:copetti.callai@gmail.com

\section{Lana de Souza Cavalcanti}

Doutora em Geografia pela Universidade de São Paulo - USP. Professora no Instituto de Estudos Socioambientais da UFG e atua no Programa de Pós-Graduação em Geografia deste instituto. Instituto de Estudos Socioambientais, Campus Samambaia da UFG - Av. Esperança, s/n CEP: 74.690-900, Goiânia - GO; E-mail:ls.cavalcanti@uol.com.br

\section{Sonia Maria Vanzela Castellar}

Doutora em Geografia pela Universidade de São Paulo - USP. Professora na Faculdade de Educação da USP e atua no Programa de Pós-Graduação em Geografia da FFLCH. Faculdade de Educação, Av. da Universidade, 308 - Butantã, São Paulo-SP, CEP: 05508-040.E-mail:smvc@usp.br

\section{Vanilton Camilo de Souza}

Doutor em Geografia pela Universidade Federal de Goiás - UFG. Professor no Instituto de Estudos Socioambientais da UFG e atua no Programa de Pós-Graduação em Geografia deste instituto. Instituto de Estudos Socioambientais, Campus Samambaia da UFG - Av. Esperança, s/n CEP: 74.690-900, Goiânia-GO.E-mail:souzavanilton@gmail.com

\section{RESUMO}

O texto apresenta uma análise das principais características dos trabalhos aprovados para o Grupo de Trabalho (GT) Ensino de Geografia do XI Encontro Nacional de Pesquisa e Pós-Graduação em Geografia (ENANPEGE). Após a leitura dos trabalhos e do relatório do GT, foi possível identificar conteúdos que se constituem em quatro grupos temáticos diferentes: metodologia de ensino de Geografia; currículo no ensino da Geografia; formação de professores de Geografia e ensino e aprendizagem em geografia. Fundamentando-se nesses trabalhos e nos estudos dos autores deste artigo, o texto traz também a síntese de elementos mais genéricos da pesquisa na área nos últimos anos, indicando aspectos da perspectiva teórico-metodológica dos coordenadores desse GT.

Palavras-chave: Ensino de Geografia; Metodologia de Ensino; Currículo e Formação de Professores. 


\begin{abstract}
This article presents an analysis of the main characteristics of the papers approved for the Geography Teaching Thematic Group (TG) at XI National Meeting of Research and Graduate Studies in Geography (ENANPEGE). After reading the papers and the TG report, was possible to identify contentes that can constitute four different groups: Geography teaching methodology; curriculum in the teaching of geography; training of Geography teachers and teaching and learning in geography. This paper is based in these works and on the preview studies from the authors of this article, the text also includes the synthesis of general elements of the research in this area during the recent years, envolving aspects of theoretical and methodological perspective from the coordinators of this TG.
\end{abstract}

Keywords: Geography teaching; Teaching Methodology; Curriculum and Teacher Education.

\title{
RESUMEN
}

El artículo presenta un análisis de las principales características de los artículos aprobado para el Grupo de Trabajo (GT) de Enseñanza de la Geografía en la XI Reunión Nacional de Investigación y Postgrado en Geografía. Después de leer los trabajos y las presentaciónes en el GT, fue posible identificar los contenidos que constituyen cuatro grupos temáticos: metodología de la enseñanza de Geografía; currículo de la enseñanza de la Geografía; formación del professorado y enseñanza y aprendizaje en la Geografía. Se basándo en estos trabajos y en los estudios de los autores de este artículo, el texto también incluye la síntesis de elementos más generales de la investigación en el área en los últimos años, incluyendo los aspectos de la perspectiva teórica y metodológica de los cordinadores de este GT.

Palabras clave: enseñanza de la Geografía; metodología de la enseñanza; plan de estudios y la formación del profesorado.

\section{A PESQUISA NO ENSINO DE GEOGRAFIA: CONSIDERAÇÕES INICIAIS}

Este artigo apresenta e discute o conjunto da pesquisa em ensino da geografia apresentado no GT Ensino de Geografia, como parte integrante da programação do XI Encontro Nacional de Pesquisa e Pós-Graduação em Geografia (ENANPEGE), realizado em 2016, na UNESP Presidente Prudente. Cabe, no entanto, apontarmos que esse GT representa parte significativa das pesquisas sobre o Ensino de Geografia no Brasil. Destacamos que de dez anos para cá notamos um incremento de investigações na temática, envolvendo maior número de pesquisadores que através de suas dissertações e teses iniciam-se de modo mais formal na pesquisa sobre o ensino da nossa disciplina escolar. Da mesma forma, vários pesquisadores tem se dedicado a aprofundar suas pesquisas, com duas vertentes que merecem ser consideradas: 1- aprofundamento teórico para as análises e 
busca de entendimento do fenômeno da educação geográfica; 2 - produção significativa de dados empíricos que sustentam e contribuem para a compreensão do fenômeno. Como desenvolvimento das atividades do GT da ANPEGE está se consolidando a tradição de reunião de estudo desse grupo com a submissão de propostas, que, após a avaliação e aceite dos textos, no decorrer do evento e nas apresentações dos trabalhos de pesquisa, deflagram discussões significativas. São questões internas e externas do fazer escolar que desafiam os nossos entendimentos e que apontam para a possibilidade de corrigir rotas e de realizar avanços importantes no ensino da disciplina. É justamente com a intenção de evidenciar os avanços dos estudos nessa área que esse texto faz um balanço dos trabalhos aprovados no contexto do GT, por entender que eles são, em certa medida, representativos da área.

Pesquisar sobre o ensino da geografia já assume identidade e tem um grupo que expressa seu pertencimento ao tema. Já não nos constituímos apenas como apêndices de outras áreas da Geografia, ao contrário, a convicção é a de que construímos um status próprio que nos garante a credibilidade de pesquisadores dessa área.

De nossa parte, como grupo coordenador deste GT, cabe ressaltar que de mais longa data estamos envolvidos com a pesquisa na temática, seja através de grupos nacionais que participamos, de grupos internacionais, com a Europa e com a América Latina, com destaque nesta referência para a Rede de Pesquisadores denominada REDLADGEO. Esta rede realiza Colóquios a cada dois anos (desde 2010 em São Paulo; 2012 em Santiago do Chile; 2014 em Buenos Aires - Argentina; e o próximo neste ano de 2016 em Bogotá Colômbia). Com base nessa rede, já temos publicações de livros e de uma revista virtual, denominada Anekumene, que é editada através da UPN- Universidad Pedagógica Nacional de Bogotá.

A nossa produção como grupo tem sido intensa, ligada às linhas de pesquisa dos Programas de Pós Graduação Stricto Sensu seja na Geografia, seja na Educação. Essa produção tem ocorrido também por meio das orientações de mestrado, de doutorado e de Pós-Doutorado, que são implementadas pelos investigadores e grupos de pesquisa institucionais cadastrados no CNPq.

Como resultado dessa trajetória da pesquisa em Ensino da Geografia,há atualmente uma produção teórica e metodológica que pode se caracterizar porcompreensões e análises de determinados conceitos e de um conjunto de categorias que vão além do ensino da disciplina especifica, mas que são parte da pesquisa em educação. Entre eles podem ser citados: Geografia Escolar; Métodos e Metodologias de Ensino; Políticas Educacionais; Currículo Escolar; Avaliação da Aprendizagem; Formação de Professores; Aprendizagem 
Escolar; Construção de Conhecimentos; Conceitos Geográficos, Cartografia Escolar, entre outros.Essa construção acontece a partir de nossos trabalhos como grupo e resulta das discussões que realizamos internamente, de modo que vamos montando um quadro teórico no decorrer de nosso trabalho como pesquisadores. Ela resulta também das orientações, no âmbito da pós-graduação a que estamos vinculados, e dos momentos em que as discussões podem ser ampliadas quando de nossa participação como palestrantes, conferencistas ou outras formas de participação nos eventos da Geografia e da Educação.

Em relação aos conceitos que tradicionalmente a Geografia considera em sua investigação, alguns tem tido particular destaque na produção do ensino de Geografia, como: espaço, território, região, paisagem, sociedade, lugar, urbano-rural, cidade, ambiente, natureza. Esses conceitos são reiteradamente conteúdos das próprias aulas de geografia, considerando-se as referências curriculares e/ou os livros didáticos, e como tal é importante ressaltar que a dimensão teórica e a empírica devem ser articuladas em sua concepção e em seu tratamento no ensino. Isso porque um dos desafios nas aulas da geografia é exatamente sair do senso comum que tem a base no empirismo e no simples fazer, para tornar os conceitos significativos para a vida do aluno. O nosso papel como docentes é fazer com que o aluno compreenda a espacialidade em que ele vive, e essa dimensão só pode ocorrer se houver um processo de abstração em que o conceito seja considerado. A escola é o lugar de fazer a abstração e a partir daí o aluno pode construir o seu aprendizado.

Como exemplo, citamos o conceito de cidade, que é em si um dos conteúdos da Geografia e que tem sido muito pesquisado e apresenta diversos resultados através da produção acadêmica. Esse é um conceito muito presente em versões anteriores do GT de Ensino de Geografia do ENANPEGE.Esse conceito tem sido,também, um dos temas que abordamos em nossas pesquisas e que expressa o estudo da cidade como o lugar de vida da maioria da população. Para entender a espacialidade, portanto, é necessário compreender a cidade como um conceito, sendo que as informações empíricas servem para dar corpo ao conteúdo trabalhado. Para entender o que acontece no cotidiano da nossa vida é fundamental o exercício da teorização e essa só pode ser feita a partir do trabalho com os conceitos. Assim, ao fazer esse exercício, o aluno tem a oportunidade de aprender intelectualmente a cidade, o que significa desenvolver com aprofundamento teórico o conteúdo.

Outro aspecto que temos como fundamental nas pesquisas sobre o ensino da Geografiadiz respeito à escala de analise, sempre necessária para dar o sentido de contextualização aos temas estudados. Com efeito, a escala tem demonstrado ser importante categoria na promoção do pensamento geográfico dos escolares.Sem a análise nessa perspectiva, a 
abordagem dos conteúdos se faz considerando os espaços de modo absoluto, perdendo assim a possibilidade de analisá-lo nas dimensões social e política de que estão recheados.

Além do que foi anteriormente destacado, outras categorias fazem parte desse quadro conceitual e são também decorrentes de temáticas que a Geografia e a educação pesquisam, conforme já mencionado: cartografia, livro didático, currículo, conteúdos, aprendizagem, ensino, formação docente, cidadania, valores, ética e estética, escola, espaço-tempo e grupo na escola, metodologias....

No que tange aos autores de referência, ressaltamos que temos como bases os pensadores da Geografia (os clássicos e os atuais) que pensam as questões teóricas e metodológicas e a dimensão epistemológica da ciência e do seu ensino. Fazem parte também da base teórica das pesquisas nessa área os autores da educação que discutem as temáticas que são adequadas a qualquer uma das disciplinas escolares e à vida e cultura escolar como um todo.

Mas, conforme indicamos inicialmente, temos um quadro teórico específico que pode embasar a pesquisa em ensino de geografia. Este tem sido construído no decorrer de nossas atividades de pesquisadores, nas reflexões que realizamos. Mas neste período a contribuição de todos os envolvidos na pesquisa sobre ensino de Geografia nos permite indicar, como resultado das reflexões presentes no GT Ensino de Geografia de 2015, um conjunto de aspectos que dão as direções para a nossa pesquisa. Estes, juntamente com as demais pesquisas que não se fizeram presentes neste GT,são importantes para compreender a Geografia escolar e podem indicar alternativas para o ensino e aprendizagem da geografia, assim como são elementos adequados para investigar (CALLAI: 2014). Os aspectos que tem norteado tais pesquisas direcionam-se por questionamentos que dizem respeito a:para quem, para quê, como, o quê.

Em para quemconsideramos que é importante (e necessário) saber quem são os sujeitos envolvidos no processo de ensino e aprendizagem da Geografia. São sujeitos que tem identidade e pertencimento ao lugar em que vivem e aos grupos sociais dos quais fazem parte. No que diz respeito apara queconsideramos os objetivos que permitem dar sentido ao que é ensinado, e principalmente qual o significado, o papel, da Geografia no conjunto do currículo escolar e a possibilidade de contribuição efetiva na sua aprendizagem pelas crianças e jovens que frequentam a escola. Para responder ao como, consideramos a importância da perspectiva teórica- metodológica de encaminhar a questão de modo a que se reconheça o significado do que está sendo estudado, ensinado e aprendido. O que trata do conteúdo a ser estudado nas aulas de geografia, tendo presente o que o jovem e a criança 
precisam saber para que tenham acesso ao conhecimento produzido pela humanidade e que se desdobra em conteúdos escolares.

Enfim, são esses os aspectos considerados na análise do conjunto de trabalhos aprovados para o GT de ensino de Geografia, a ser desenvolvida na parte seguinte do texto.

\section{A PESQUISA NO ENSINO DE GEOGRAFIA REPRESENTADA NO GRUPO DE TRABALHO DO ENANPEGE}

A parte introdutória do artigo, além de sintetizar elementos mais genéricos da pesquisa na área nos últimos anos, indica também elementos da perspectiva teórica e metodológica de quem leu os trabalhos selecionados para o GT, e de quem coordenou as discussões do mesmo durante o ENANPEGE. Com essas bases, o artigo apresenta a seguir uma breve caracterização dos trabalhos sobre Ensino de Geografia aprovados nesse evento e uma possível categorização de suas temáticas.

\section{CARACTERIZAÇÃO DOS TRABALHOS APRESENTADOS NO GT ENSINO DE GEOGRAFIA}

Foram aprovados e publicados 48 trabalhos do GT nos anais do XI ENANPEGE, sendo os mesmos apresentados em duas modalidades: seção pôster e grupo de discussão. Na última modalidade foram apresentados 31 trabalhos. Vale destacar, no entanto, que alguns autores de pôster participaram também do grupo de discussão dos trabalhos apresentados oralmente, na qual estavam presentes ainda outros participantes do Evento que não haviam inscrito nenhum trabalho, ampliando assim a discussão, conforme podemos verificar no quadro 01 :

Quadro 01: Tipo de participantes no grupo de discussão do GT Ensino de Geografia durante o XI ENANPEGE - 2015

\begin{tabular}{l|l}
\multicolumn{1}{c|}{ PARTICIPANTES } & QUANTIDADE \\
\hline Apresentaram no grupo de discussão & 31 \\
\hline Participaram no grupo de discussão sem trabalhos inscritos & 07 \\
\hline Inscreveram na seção pôster e participaram do grupo de discussão & 04 \\
\hline Coordenadores do GT & 02 \\
\hline
\end{tabular}

Vale destacar que, para a produção deste texto, tomamos como referência todos os trabalhos publicados ${ }^{1}$ nos Anais do XI ENANPEGE, 48 no total, sendo agrupados em quatro diferentes temas: metodologia de ensino de Geografia; currículo no ensino da Geografia (texto didático/livro); formação de professores de Geografia; e ensino e aprendizagem em geografia.

\footnotetext{
Apesar de os trabalhos escritos serem a principal referência empírica para o trabalho, utilizaremos algumas informações pre-
} sentes no grupo de discussão, momento em que foram apresentados oralmente os trabalhos.

a 
Como forma de ilustrar algumas informações sobre o conjunto dos trabalhos apresentados no evento, categorizamos as palavras-chave contidas nos trabalhos publicados no evento, contabilizando um total de 158 palavras-chave. Dessas, 55 palavras não se repetem e 103 foram assim agrupadas: Ensino de geografia (30), Geografia (12), Formação de professores (07), Cartografia/mapas (14), Aprendizagem (06), Novas tecnologias (07), Currículo/textos de geografia (09), Trabalho de campo (03), Lugar (03), Construção do conhecimento (02), Educação ambiental (03), Educação escolar indígena (02), Anos iniciais (02), Interdisciplinaridade (03).

A palavra-chave "Ensino de Geografia" destaca-se como a mais citada, o que é coerente inclusive com o nome do nosso GT. Vale destacar que o quantitativo de palavras-chave que se repetiram comumente nos trabalhos se coadunam com a quantidade de temáticas que agrupamos para compor o estado da arte desse GT. A seguir, destacaremos as especificidades de cada temática agrupada a partir dos trabalhos aprovados e algumas reflexões sobre a mesma nas atuais pesquisas sobre o Ensino da Geografia.

\section{A CARTOGRAFIA NO ENSINO DE GEOGRAFIA}

Uma das temáticas apresentadas no GT foi a cartografia escolar. Ressaltamos a importância dessa linha de pesquisa, porque estudar Geografia por meio da Cartografia implica pensar o espaço, pensar e falar sobre a realidade e, ao mesmo tempo, desenvolver o raciocínio espacial. Ler o mundo significa para a geografia escolar compreender a complexidade espacial e as várias dimensões da escala de análise - local, global, regional-, para que os alunos possam mostrar como pensam os lugares vividos e aqueles não vividos, ou seja, como veem, percebem ou concebem o mundo.

As pesquisas sobre representação cartográfica no ensino da Geografia podem ser um caminho para, por meio da elaboração de croquis, dos desenhos, dos percursos, por exemplo, analisar a realidade superando abordagens dicotômica e/ou fragmentada da realidade, compreendendo os arranjos e configurações espaciais da paisagem possibilitando propostas de ensino que contribuam mais efetivamente para a educação básica. Isso porque ao representarem os elementos que compõem a paisagem, a observação e a análise dela são fundamentais para identificar a produção e a organização do espaço, a relação entre natureza, sociedade mediado pelo trabalho e dessa maneira o aluno terá condição de entender os conceitos geográficos e fazer a leitura do mundo.

O propósito de trabalhar com a cartografia, como uma linguagem para ensinar geografia, é propiciar as construções de representações a partir de descrições ricas das paisagens por meio das observações que os alunos fazem da realidade e, ainda, relacionar 
com as mudanças temporais que ocorreram nos lugares. Desta maneira privilegia-se o cotidiano, as diferentes paisagens e modos de vida, proporcionando uma riqueza conceitual que o professor pode escolher para desenvolver suas aulas de geografia, tais como: paisagem, região, território, sociedade, urbano, entre outros. (CASTELLAR:2015)

Neste contexto é que atualmente encontramos por meio de vários trabalhos apresentados na ANPEGE e, também, em outros eventos acadêmicos, como o da Sociedade Internacional de Cartografia, Congresso de Cartografia para crianças, resultados parciais e totais de pesquisa voltados para o ensino e aprendizagem da cartografia. Como tema das pesquisas apresentadas com o tema da cartografia escolar destacamos: a construção de conceitos cartográficos em alunos do ensino fundamental; os mapas e representações e sua contextualização nos livros didáticos e, ainda, a importância do raciocínio espacial em crianças. Algumas dessas pesquisas mais recentes tem a influência de pesquisadores geógrafos norte-americanos. Há, ainda, outras vertentes que tratam a cartografia como representações sociais, imagens, articulando com diferentes linguagens. Além disso, estão presentes tambémestudos relacionados com o uso de tecnologia computacional e suas derivações, que fazem parte do acervo das pesquisas em cartografia.Isso significa que do ponto de vista das investigações ainda há muito que se estudar e pesquisar em cartografia.

\section{AS PESQUISAS EM TORNO DAS METODOLOGIAS DE ENSINO DE GEOGRAFIA}

Com relação ao tema Metodologia de Ensino de Geografia, tivemos 18 trabalhos aprovados. Desses, 10 estudos continham propostas voltados à cartografia, dois com propostas ligadas à Geotecnologias, dois discutindo o conceito lugar como caminho de abordagem dos conteúdos no ensino da Geografia, um sobre trabalho de campo e três com procedimentos didáticos relacionados ao uso de games, música e jogos teatrais no ensino da Geografia.

A preocupação com as metodologias de ensino é tradicional na área, pois responde a uma demanda mais imediata do professor, que está sempre em busca de formas de suscitar e garantir o interesse dos seus alunos nas aulas e nos conteúdos de Geografia. Movidos por essa motivação, os professores fazem escolhas de tipos aulas e usam recursos didáticos que permitem ultrapassar o modelo mais convencional de aulas expositivas, valendo-se para isso de dinâmicas de grupos, dramatizações, atividades com pesquisas, uso de recursos tecnológicos, linguagens alternativas (música, poesia, cinema).

Entendemos que essa preocupação é legitima, no entanto, temos buscado alertar os professores de que um interesse real do aluno não pode estar ligado à forma de trabalho, mas ao conteúdo e a todo o processo de ensino, o que exige uma elaboração consciente 
das aulas, no sentido de articular objetivos, conteúdos e métodos. Ou seja, as formas de operacionalizar o ensino (que são os caminhos metodológicos e as técnicas) não podem estar desvinculadas dos propósitos do ensino e devem ser selecionadas de acordo com os conteúdos para que sejam de fato eficazes do ponto de vista da aprendizagem dos alunos e não se constituam apenas em modos de "variar" as aulas, tornando-as mais dinâmicas.

Nesse sentido, os trabalhos apresentados no Evento tem se constituído em formas de reflexão mais aprofundada sobre a prática docente, que articula os objetivos às formas de ensinar, ampliando, assim, a discussão sobre métodos e metodologias de ensino.

\section{AS PESQUISAS FOCADAS EM TEMAS DE ORIENTAÇÕES CURRICULARES E POLÍTICAS EDUCACIONAIS}

Com referência aos dez trabalhos que compuseram o tema Currículo no Ensino de Geografia, por sua vez, contamos com quatro trabalhos que versaram sobre o livro didático e o conteúdo de geografia. Três trabalhos versaram sobre o currículo de Geografia na Educação Básica, dois trabalhos sobre o currículo na Educação Superior e um trabalho sobre política pública e ensino de geografia.

As políticas educacionais no Brasil, traduzida nas normativas, nas referências oficiais de conteúdos escolares e nas reformas do sistema, resultam em constantes alterações que interferem tanto na formação dos professores quanto em suas práticas profissionais cotidianas, o que justifica, de fato, a presença de um conjunto de trabalhos com essa temática. Essas políticas têm focado a formação do professor,tanto a inicial quanto a continuada. Em outro polo, elas têm focado também as referências curriculares, com o objetivo de definir conteúdos para a educação básica. Na entanto, essa mesma política exige competências do professor em termos de eficiência, de resultados traduzidos em indicadores das avaliações, a partir de parâmetros/padrões nacionalmente definidos - pelo poder regulador do Estado. E, ao lado disso, os maus resultados tem sido freqüentemente atribuídos à precariedade do seu trabalho.

Esse quadro estrutural das políticas educacionais mais recentes impõe limites e provoca insegurança do professor, por um lado, mas, por outro, gera resistências, seja na ordem do discurso do professor, seja em movimento de oposição mais organizado, seja na busca de investigações, como as representadas no GT, para uma compreensão mais consistente dos fundamentos da política e de seus desdobramentos na prática docente. 


\section{A FORMAÇÃO DE PROFESSORES DE GEOGRAFIA NO XI ENANPEGE}

Os seis trabalhos que compuseram o tema formação de professores se caracterizam por três textos sobre formação inicial, dois sobre identidade e formação docente e um texto sobre a formação de professores para os anos iniciais.

A formação inicial de professores de Geografia tem se constituído nos últimos tempos objeto de inúmeras pesquisas, além de ser tema de grande destaque nas agendas das políticas públicas de educação. Um aspecto que se faz presente tanto na pesquisa como nas políticas tem girado em torno da qualidade do profissional para o momento atual. A preocupação tem sido, no entanto, mais do que afirmar essa qualidade, mas apresentar propostas para viabilizar essa qualidade de formação de professor, no sentido de torna-lo um profissional capaz de possibilitar a construção do conhecimento para as atuais gerações de alunos que se encontram em um mundo em que as informações (que por vezes é denominada de conhecimento geográfico, no caso) são fluidas e voláteis.

Consideramos que a formação inicial do professor de Geografia é o momento apropriado para se desenvolver conhecimentos da ciência articulado aos contextos escolares criando uma identidade própria para esse contexto. Uma dimensão importante nesse processo é a valorização do profissional que seria uma tarefa central das políticas públicas da educação. De modo diferente, percebe-se que elas não têm apresentado condições concretas para atingir esse fim.

As pesquisas, sob o nosso ponto de vista, têm procurado, dentre outras coisas, apontar caminhos para a valorização desse profissional e para construção de uma identidade capaz de levar a cabo o professor que desejamos. Consideramos a pesquisa uma atividade no processo de formação de professores capazes de desenvolverem uma ação como sujeito real e concreto na profissão. Pela pesquisa, julgamos ser possível a alteração do tradicional modelo de formação de professores rumo à inserção crítica e transformadora na realidade escolar considerando, nesse processo, as interfaces necessárias entre os conhecimentos da ciência e os saberes dos alunos, para, então, construir saberes geográficos concretos condizentes com as ações sociais e culturais dos sujeitos. Assim, julgamos que a pesquisa na formação do professor de Geografia deve ocorrer no contexto do ensino dessa disciplina tendo a escola como foco central.

Destacamos ainda que a pesquisa na formação do professor deve ser entendida como aquela capaz de superar a dicotomia entre teoria e prática, entre universidade e escola, entre Geografia Acadêmica e Geografia Escolar. Tanto a escola como a universidade são capazes de produzir colaborativamente a Geografia e o seu ensino (CAVALCANTI e SOUZA, 2014). 
Para tanto, consideramos fundamental a superação da ideia de que a pesquisa se desenvolve apenas na universidade e que somente nesse espaço se produz o conhecimento. Pela pesquisa na formação de professores de Geografia tem-se evidenciado que é fundamental articular o domínio dos conteúdos específicos, o como ensinar e o sentido desses conteúdos com o dia a dia dos alunos. Para as práticas investigativas, inclusive aquelas que ocorrem na escola, devemos considerar os fundamentos teóricos dos conteúdos geográficos, como esses conteúdos formam pensamento espacial nos alunos, que linguagens são mais eficazes no desenvolvimento desses conteúdos e como eles estabelecem relação com a vida cotidiana. É em função do pensamento espacial que se deseja construir, que se opera metodologicamente uma ação investigativa, seja para a formação do professor, seja para a sua atuação na escola. Saber perguntar sobre o espaço, saber levantar hipóteses, saber levantar informações geográficas e dialogar com os conteúdos/conceitos são dimensões centrais da pesquisa que podem e devem ser contempladas nesse processo de formação.

Por meio de pesquisas sobre a formação inicial (e também na atuação profissional na escola) tem-se apontando o quanto é imprescindível superar as bases do ensino pela transmissão. Defendemos a ideia de que em um processo investigativo a aprendizagem é decorrente de uma construção autônoma por parte de quem aprende. Ao professor cabe o papel de orientar seus alunos nesse processo de aprendizagem utilizando-se dos conhecimentos da Geografia e dos recursos didáticos eficazes ao processo de construção do conhecimento por parte do aluno.

\section{AS PESQUISAS SOBRE ENSINO-APRENDIZAGEM DE GEOGRAFIA}

Em relação ao último tema,o Ensino e Aprendizagem em Geografia, foram identificados 14 trabalhos aprovados, dentre os quais sete discutem o ensino por conceitos, cincoabordam práticas pedagógicas no ensino da disciplina e doistratam do ensino de geografia para populações indígenas.

Sobre essa temática, é relevante destacar o tema da formação de conceitos, que tem sido um tema de pesquisa muito presente entre os estudiosos da área de ensino de Geografia, sobretudo aqueles que se fundamentam em contribuições de Vygotsky (1984, 2000). Seguindo as contribuições desseautor, há uma relação necessária entre cotidiano, mediação pedagógica e formação de conceitos no desenvolvimento do processo de ensinoaprendizagem. Para a Geografia, alerta-se para a relevância dos conhecimentos cotidianos dos alunos, especialmente a respeito do lugar onde vivem e suas representações sobre os diferentes lugares do globo. Nessa orientação, é importante que o professor compreenda os significados que os alunos dão aos conceitos científicos que são trabalhados no ensino. 
Para formar um pensamento espacial, é necessário que eles formem conceitos geográficos abrangentes, que são ferramentas fundamentais para a compreensão dos diversos espaços, para localizar e analisar os significados dos lugares e sua relação com a vida cotidiana.

A meta de formação de conceitos geográficos no ensino explicita uma compreensão de que ensinar Geografia não é ensinar um conjunto de conteúdos e temas, mas é, antes de tudo, ensinar um modo de pensar, um modo de perceber a realidade, um modo de percebêla espacialmente. O desenvolvimento do pensamento conceitual, que permite uma mudança na relação do sujeito com o mundo, generalizando suas experiências, é papel da escola e das aulas de Geografia. Orientar-se por essa meta não implica em apresentar definições para serem reproduzidas pelos alunos. Os conceitos, na realidade, são construídos, elaborados, reelaborados, ampliados, ao longo dos anos de ensino fundamental.

\section{CONSIDERAÇÕES FINAIS}

No que diz respeito a este momento do GT que foi realizado no Enanpege de Presidente Prudente (2015), além dos dados produzidos, vale destacar que há um envolvimento significativo de pesquisadores da área, que estavam presentes em todas as discussões, o que pode ser atestado pelas constatações a seguir:

- Verificamos uma evolução qualitativa dos trabalhos apresentados no GT. Maior rigor teórico metodológico, maior clareza dos objetos de pesquisa voltados ao ensino da geografia, boa relação problemática/objetivo/metodologia da pesquisa, maior cuidado com a linguagem acadêmica, dentre outros aspectos.

- Boa frequência no GT nos dois dias e do início ao fim de cada dia. Muito interesse nas discussões e intervenções pertinentes.

Portanto, pode-se inferir que essa é uma área em expansão e aprofundamento teóricometodológico, o que pode ser verificado tanto pela quantidade de trabalhos apresentados quanto pela diversidade temática contemplada. 


\section{REFERÊNCIAS}

1. CALLAI, H.C. Em busca de fazer a educação geográfica. In: CALLAI, H.C.(org.) Educação Geográfica - Reflexão e Prática. Coleção Ciências Sociais. Editora Unijui. Ijui (RS). 2014.

2. CASTELLAR, Sonia M.V. Ensinar Geografia por meio da Cartografia escolar: o raciocínio espacial. In RABELO, K. e BUENO, M. (orgs.) Currículo, políticas públicas e ensino de geografia. Goiás, Ed. PUC-Goiás, NEPEG, p. 195-212. 2015.

3. CAVAlCANTI, L. de S. e SOUZA, V. C.de 2014 A formação do professor de Geografia para atuar na educação cidadã. Scripta Nova. Barcelona (Es.), v. 18, p. 1-17. 2014.

4. VYGOTSKY, L. S. Formação social da mente. São Paulo: Martins Fontes, 1984.

5. . A construção do pensamento e da linguagem. São Paulo: Martins Fontes, 2000.

Artigo recebido em 1 de maio de 2016.

Artigo aceito em 1 de junho de 2016. 